There are four areas of service in which further progress is needed:

O The current day hospital is under the management of the community team and it renders its services to adult populations only. Other categories of psychiatric patients needing such services are the elderly, people with an intellectual disability and adolescents.

O Another challenge is the establishment of sheltered employment for all categories of psychiatric patient. The Bahraini labour law stipulates that $5 \%$ of the working population's employment opportunities should be allocated to people with special needs. In a competitive job market this is difficult to attain, making sheltered employment a challenging but helpful solution.

Both community and day patient facilities still need to be expanded.

O Improvement is still needed in psychiatric services in primary care (by furthering family physicians' training in psychiatry).

\section{References}

Al-Haddad, M. K. (1988) Bahrain Mental Health Programme Till the Year 2000. Ministry of Health.

Al-Haddad, M. K. (1997) Mental and Psychological Health Plan. Ministry of Health.

Al-Haddad, M. K. \& Al-Offi, A. (1996) History of psychiatric services in Bahrain. Journal of the Bahrain Medical Society, 8, 127-131.

Al-Haddad, M. K., Khashaba, A. S., Baig, B. Z., et al (1994) HIV antibodies among intravenous drug users in Bahrain. Journal of Communicable Diseases, 26, 127-132.

Bibby, G. (1969) Looking for Dilmun. New American Library.

Central Statistics Organisation Directorate (1991) Bahrain in Figures. Government of Bahrain.

Clark, A. (1981) The Island of Bahrain. Historical and Archeological Society, Bahrain

Derbas, A. \& Al-Haddad, M. K. (2001) Factors associated with relapse among opiate addicts in Bahrain. Eastern Mediterranean Health Journal, 7, 473-480.

Royal College of Psychiatrists (2002) Model Consultant Job Descriptions and Recommended Norms (occasional paper OP55). RCPsych.

\title{
Sudan's national mental health programme and burden of mental illness
}

\author{
Ehab Ali Sorketti MBBS Sudan MPM (Psychiatry) UM Malaysia
}

Mandag General Hospital, Mandag PO Box 117, Al Baha Region, Kingdom of Saudi Arabia

Suda udan occupies $2500000 \mathrm{~km}^{2}$ in East Africa. It has borders with nine countries, two of which are Arab: Egypt, Libya, Kenya, Uganda, Congo, Chad, the Central African Republic, Ethiopia and Eritrea. Sudan is the largest country in Africa. The heart of the country, in terms of population, lies at the confluence of the Blue and White Niles. The complex of the 'three towns', comprising the three largest cities, Khartoum, Khartoum North and Omdurman, is situated there and contains almost 20\% of the population. The total population of Sudan is about 35.4 million (projected from the 2005 census). The urban population was estimated at 33\% of the total. About 2.2 million are still entirely nomadic. Sudan's peoples are as diverse as its geography. There are 19 major ethnic groups and 597 subgroups.

The Sudanese population is very young, with $43.1 \%$ below the age of 15 years and only $2.7 \%$ above the age of 65 (1994 figures). In 2000, the total adult literacy rate and the female adult literacy rate were estimated at 50\% and $49 \%$ respectively. The crude annual death rate is 11.5 per 1000 population and the crude birth rate is 37.8 per 1000 population (2004). The infant mortality rate is estimated at 68 per 1000 live births, and the under- 5 mortality rate is 104 per
1000 live births. Total life expectancy at birth was 56.6 years in 2000. The maternal mortality rate is estimated at 50.9 per 10000 live births (2000).

Widespread poverty and the erosion of household coping capacities due to war make a large segment of the population vulnerable to food insecurity brought on by crises such as flooding, drought, conflict and displacement. Regional and urban/rural disparities in economic resources have clear implications for health and nutrition as well as service provision.

Psychiatry in Sudan began in the 1950s under the guidance of the late Professor Tigani El Mahi, the father of African psychiatry. He pioneered, among other things, rural services and the open-door policy. His successor, Dr Taha A. Baasher, shouldered the responsibility and further extended services to the periphery.

\section{The national mental health programme}

\section{Targets of the programme}

The guiding principles are: close integration of essential mental healthcare with the general health system, and in 
particular the primary care setting; development of training programmes for health personnel at all levels of the health service; development of an appropriate referral system, with comprehensive recording of information; provision of essential drugs; and community involvement and close collaboration with other social sectors, agencies and organisations.

\section{Progress}

In 1990, a mental health unit in the Ministry of Health was established. There is now a mental health board, supported by the Sudanese Psychiatric Association, which acts as an advisory body to the Minister of Health. Decentralisation to district general hospitals occurred in the early 1960s, and has now been implemented at the primary care level. Training courses are available for undergraduates, psychiatric specialist trainees and medical officers.

Attention has been given to special groups such as migrants, vagrants, the elderly, refugees and the displaced, as well as uncared for children. School mental health has been incorporated into the Mental Health Programme. A list of essential drugs has been formulated.

\section{Administrative and managerial issues}

In view of the fact that in the past 2 years the number of states in the country has increased from 10 to 25, an essential priority in the plan of action is the establishment of mental health services in these new states. An important priority in this respect is logistics.

\section{Human resources development}

In the plan of action for the programme, training is the foremost priority. A 4-year postgraduate course leading to an MD in psychological medicine was initiated in 1989. The postgraduate training programme is a current priority.

\section{Evaluation}

Though efforts have been made to evaluate the implementation of the mental health programme, more systematic planning and follow-up are required.

\section{Research}

Mental health research in Sudan has a long history, including collaboration with the World Health Organization and other bodies.

\section{Mental health policy}

Sudan's mental health policy was initially formulated in 1998. The components of the policy are advocacy, promotion, prevention, treatment and rehabilitation.

\section{Substance misuse policy}

The substance misuse policy was initially formulated in 1995.

\section{National therapeutic drug policy}

The national therapeutic drug policy, which includes a list of essential drugs, was formulated in 1970.

\section{Mental health legislation}

The most recent legislation is the Gezira Mental Health Law of 1998. Mental health is also the subject of one chapter of the Public Health Act of 1973, which was revised in 1985. A Mental Health Act has been drafted and has gone to parliament for approval.

\section{Mental health financing}

There are budget allocations for mental health, but details of expenditure on mental health are not available. The primary source of mental health financing is taxation. The country has disability benefits for persons with mental disorders.

\section{Mental health facilities}

\section{Primary care}

Treatment of severe mental disorders is not available at primary care level.

Traditional healers are often used for the provision of mental health services. In Sudan, a symbiotic working relationship has been developed with faith healers over more than 30 years, as part of community-based mental health programmes. There was a great deal of initial resistance from the faith healers, who saw mental health professionals as competitors, but a non-confrontational approach brought home the message that indeed there are areas, particularly cases of emotional disorder, where collaboration between the two is possible. Such collaboration has gradually been formalised in order to set up referral channels for people with mental and neurological illnesses, particularly psychoses and epilepsy.

There are no community care facilities for patients with mental disorders. Community care is absent due to the lack of transportation, lack of social workers and poor health education.

\section{Psychiatric beds and professionals}

Many mental health professionals, including most psychiatrists, have left for other countries (World Health Organization, 2006). The numbers remaining are shown in Table 1.

Table 1 Numbers of beds and mental health professionals in Sudan

$\begin{array}{ll} & \begin{array}{l}\text { National } \\ \text { provision }\end{array} \\ \begin{array}{ll}\text { Numbers of psychiatric beds per } 10000 \text { population } \\ \text { Total number of psychiatric beds }\end{array} & 0.20 \\ \quad \text { of which in mental hospitals } & 0.18 \\ \quad \text { of which in general hospitals } & 0.02 \\ \text { Psychiatric beds in other settings } & 0 \\ \text { Numbers of professionals per 100000 population } & \\ \text { Psychiatrists } & 0.09 \\ \text { Neurosurgeons } & 0.007 \\ \text { Psychiatric nurses } & 0.2 \\ \text { Neurologists } & 0.014 \\ \text { Psychologists } & 0.17 \\ \text { Social workers } & 0.1\end{array}$


Table 2 Patient numbers in Sudan, 2005 and 2006, by gender and diagnosis

\begin{tabular}{|c|c|c|c|}
\hline & Male & Female & Total \\
\hline \multicolumn{4}{|c|}{ Total numbers of patients discharged } \\
\hline \multicolumn{4}{|c|}{ Schizophrenia } \\
\hline 2005 & 530 & 308 & 838 \\
\hline 2006 & 1175 & 788 & 1963 \\
\hline \multicolumn{4}{|c|}{ Other psychosis } \\
\hline 2005 & 867 & 718 & 1585 \\
\hline 2006 & 1575 & 1237 & 2812 \\
\hline \multicolumn{4}{|l|}{ Epilepsy } \\
\hline 2005 & 505 & 334 & 831 \\
\hline 2006 & 564 & 825 & 1419 \\
\hline \multicolumn{4}{|c|}{ Out-patient attendance } \\
\hline \multicolumn{4}{|c|}{ Schizophrenia } \\
\hline 2005 & 3157 & 2072 & 5229 \\
\hline 2006 & 4136 & 2739 & 6875 \\
\hline \multicolumn{4}{|c|}{ Other psychosis } \\
\hline 2005 & 4331 & 4342 & 8673 \\
\hline 2006 & 10134 & 9525 & 19659 \\
\hline \multicolumn{4}{|l|}{ Epilepsy } \\
\hline 2005 & 2812 & 2204 & 5016 \\
\hline 2006 & 4357 & 3682 & 8039 \\
\hline
\end{tabular}

\section{The burden of mental illness}

Total numbers of patients, by diagnosis and gender, for both 2005 and 2006, are given in Table 2.

\section{References}

Ahmed, I. M., Bremer, J. J., Magzoub, M. M. E., et al (1999) Characteristics of visitors to traditional healers in central Sudan. Eastern Mediterranean Health Journal, 5, 79-85.

Sudan Federal Ministry of Health National Information Centre. The Annual Health Statistical Report 2005-2006.

World Health Organization (2001) Sudan Country Profile. WHO.

World Health Organization (2001) World Health Day Documents 2001. Mental Health as Part of Primary Health Care: Highlights from the Region. WHO, EMRO.

World Health Organization (2006) Mental Health in the Eastern Mediterranean Region: Reaching the Unreached. WHO Regional Publications, Eastern Mediterranean Series.

\section{Use of participatory, action and research methods in enhancing awareness of mental disorders in Kariobangi, Kenya}

\section{Caleb J. Othieno, ${ }^{1}$ Nelly Kitazi, ${ }^{2}$ James Mburu, ${ }^{1}$ Anne Obondo, ${ }^{1}$ Muthoni A. Mathai ${ }^{1}$ and Rene Loewenson ${ }^{3}$}

'Department of Psychiatry, PO Box 19676, Kenyatta National Hospital, 00202 - KNH, Nairobi, Kenya, email cjothieno@uonbi.ac.ke; ${ }^{2}$ Mathari Hospital, Nairobi, Kenya; ${ }^{3}$ Training and Research Support Centre, EQUINET

W orldwide, mental disorders affect 450 million people and account for $15 \%$ of the overall burden of diseases from all causes (World Health Organization, 2001). Two-thirds of those affected do not receive adequate care owing to stigma, discrimination, neglect and poverty. The World Health Organization (2001) found that only $1 \%$ of the total health expenditure went to mental health in most countries.

In Kenya, service provision is further impeded by limited facilities and lack of mental health workers. Milder forms of psychiatric disorder (especially those affecting children, who comprise a large part of the population) are not adequately identified (Kiima et al, 2004). Plans to increase access to mental health services mainly use the top-down approach, instead of involving community members in planning. The First Kenya National Mental Health Programme of Action, in 1996, emphasised the need for the development of infrastructure and the training of mental health workers but gave little detail on community involvement, although it recognised the need to improve community services. This paper describes an attempt to involve community members and primary health workers in identifying and working out solutions to mental health problems in a socio-economically disadvantaged area in Nairobi, Kenya, using participatory, reflection and action (PRA) methods. PRA methods empower people to share, analyse, enhance their knowledge and plan further actions after evaluation and reflection (Wadsworth, 1998). Although the methods have been used successfully in other areas of rural development, their use in relation to psychiatric services has not been reported in Kenya.

\section{Method}

Over a 6-month period, in 2007, 30 community members from Kariobangi and community mental health workers based at Mathari Hospital were selected and engaged in a PRA process to identify mental health challenges and to enhance the community's problem-solving capacity. During the first meeting, a baseline questionnaire was administered to assess the participants' perception of mental health and the stigma associated with it, and the role of families and social organisations in promoting mental health. Thereafter, concepts of mental health were discussed using health pictures. Through brainstorming and group discussions, the mental health problems were ranked and scored on charts 